\title{
Effect of precipitation inhibitors on supersaturation and solubility of furosemide
}

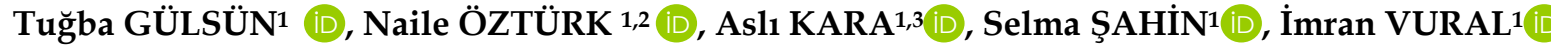

1 Department of Pharmaceutical Technology, Faculty of Pharmacy, Hacettepe University, Ankara, Turkey.

2 Department of Pharmaceutical Technology, Faculty of Pharmacy, İnönü University, Malatya, Turkey.

3 Department of Medical Services and Techniques, Sungurlu Vocational High School, Hitit University, Çorum, Turkey.

* Corresponding Author. E-mail: sahin.selma@gmail.com (S.S.); Tel. +90-312-305 1241.

Received: 17 December 2020 / Revised: 04 March 2021 / 09 March 2021

ABSTRACT: Furosemide is a widely used diuretic drug for the treatment of edema associated with heart, liver cirrhosis, renal diseases and hypertension. It is a Class IV drug with low aqueous solubility and low permeability according to Biopharmaceutics Classification System (BCS). Furosemide was chosen as a model drug to examine the effect of polymeric precipitation inhibitors (PPIs) on the supersaturation and solubility. Solubility and concentration change of furosemide as a function of time at $\mathrm{pH} 1.2$ and 6.8 were determined to show the effects of PPIs on furosemide solubility. The $24 \mathrm{~h}$ equilibrium solubility of furosemide was $0.017 \pm 0.004$ and $3.62 \pm 0.201 \mathrm{mg} / \mathrm{mL}$ at $\mathrm{pH}$ 1.2 and $\mathrm{pH} 6.8$ buffer solutions, respectively. PPI type and concentration $(0.05 \%, 0.25 \%)$ did not increase furosemide solubility at $\mathrm{pH}$ 1.2. However, both hydroxypropylmethylcellulose (HPMC) and polyvinylpyrrolidoneK17 (PVPK17) at two concentrations increased furosemide solubility at $\mathrm{pH} 1.2$ and 6.8. In addition, viscosity of solutions was in the range of 2.2-3.7 centipoise, and it was not influenced by PPIs concentrations. Our results showed that designing supersaturated formulations using PPIs can be useful and promising to enhance solubility of furosemide.

KEYWORDS: Furosemide; precipitation inhibitors; solubility; supersaturation.

\section{INTRODUCTION}

One of the major challenges that pharmaceutical companies encounter during the drug development process is to develop a commercial product with a sufficient pharmacokinetic profile from poorly watersoluble drugs. This process is both time consuming and costly. In addition, most of the newly developed drug candidates have also poor permeability characteristics. Solubility is an important physicochemical property as it affects the absorption, bioavailability and onset of action of a low solubility compound [1]. Therefore, it is necessary to increase the solubility of compounds to overcome bioavailability problems. Various approaches are used to increase the solubility of compounds, including the use of different polymorphic/amorphic drug forms, reduction of particle size, addition of surfactants or cosolvents to the formulation, complexation, $\mathrm{pH}$ adjustment, solid dispersion, new formulation techniques, precipitation inhibitors to create supersaturable formulations [2].

Strategies to increase absorption of the poorly water-soluble drugs focus mainly on increasing equilibrium solubility and improving the rate of dissolution in the gastrointestinal fluids. In addition, maintaining the poorly water-soluble drugs in a transient supersaturated state in intestinal fluids, long enough to achieve sufficient absorption, emerges as another feasible approach [3,4]. Supersaturated state of solute is defined as the state where the solute concentration in solution is higher than the equilibrium solubility. If this situation is maintained even temporarily, absorption may increase. However, as drugs are not thermodynamically stable at high concentrations, they tend to precipitate in the body, resulting in low and variable bioavailability. To overcome this problem, precipitation inhibitors are commonly used to keep drugs in a supersaturated state [4]. Polymers such as cellulose derivatives, polyvinylpyrrolidones,

How to cite this article: Gülsün T, Öztürk N, Kara A, Şahin S, Vural i. Effect of precipitation inhibitors on supersaturation and solubility of furosemide. J Res Pharm. 2021; 25(2): 209-217. 
cyclodextrins and methacrylates are the most commonly utilized precipitation inhibitors in oral formulations [5]. When the supersaturated formulations prepared with precipitation inhibitors reach the gastrointestinal fluids, drug concentration exceeds its equilibrium solubility. As the drug precipitation is delayed by the precipitation inhibitors, high drug concentration provides improved absorption and potential increase in the bioavailability of poorly water-soluble drugs [6]. In this study, supersaturated formulations were prepared using precipitation inhibitors to improve solubility of furosemide.

Drugs are categorized into four classes as Class I (high permeability and high solubility), Class II (high permeability and low solubility), Class III (low permeability and high solubility), Class IV (low permeability and low solubility) according to BCS [7]. Ten years after BCS, Wu and Benet developed Biopharmaceutics Drug Disposition Classification System (BDDCS) by replacing permeability with metabolism. BDDCS classifies drug substances in four classes based on aqueous solubility and metabolism (Class I: high solubility and extensive metabolism; Class II: low solubility and extensive metabolism; Class III high solubility and poor metabolism; Class IV: low solubility and poor metabolism) and provides information in regard to drug-drug interactions, and role of transporters in drug absorption and elimination [8].

The model drug furosemide (5-(aminosulphonyl)-4-chloro-2-[(2-fuanyl-methyl) amino] benzoic acid) is a diuretic drug used for the treatment of edema associated with heart, liver cirrhosis, renal diseases and hypertension for many years [9]. As shown in Figure 1, furosemide is commercially available as tablets (20, 40 and $80 \mathrm{mg}$ single dose), solutions $(10 \mathrm{mg} / \mathrm{mL}, 40 \mathrm{mg} / 5 \mathrm{~mL})$ and injections $(10 \mathrm{mg} / \mathrm{mL})$. According to BCS and BDDCS, it is classified as a Class IV drug with low aqueous solubility, low permeability and poor metabolism [10-12]. Its bioavailability is low and highly variable (37-70\%). Absorptive and efflux transporters effects could be important for furosemide. Therefore, increasing solubility of furosemide is quite critical for furosemide formulations to enhance its absorption and bioavailability.<smiles>NS(=O)(=O)c1cc(C(=O)O)c(NCc2ccco2)cc1Cl</smiles>

Figure 1. Chemical structure of furosemide.

The aim of this study was to investigate the effect of polymeric precipitation inhibitors (PPIs) such as PolyvinylpyrrolidoneK17 (PVPK17) and hydroxypropylmethylcellulose (HPMC) at various concentrations on the supersaturation and solubility of furosemide. For this purpose; solubility, concentration change and viscosity of furosemide as a function of time at $\mathrm{pH} 1.2$ and 6.8 were determined in this study.

\section{RESULTS AND DISCUSSION}

\subsection{Effects of PPIs on furosemide solubility}

Poorly water-soluble drugs can be formulated as solid dispersions, lipid-based systems or nanoparticles to enhance their bioavailability [13-15]. These drug-delivery systems are called high energy drug delivery technologies, and solid-state or solution-state supersaturation are produced with these technologies. Solution-state supersaturation is especially important to obtain higher bioavailability [16, 17]. PPIs such as HPMC and PVP have supersaturation maintenance effect but, this effect varies for different drugs so, it is imperative to understand their effect on drugs with a case by case approach. Maintenance of solution supersaturation by PPIs are explained by different hypotheses [13]. In the first hypothesis, PPIs can enhance viscosity and thus, diffusivity of drugs is reduced and drug nucleation and crystal growth are inhibited. According to the second hypothesis, PPIs prevent crystal growth by acting at crystal-solution interface to inhibit attachment of molecules from solution to crystal body. And lastly, PPIs enhance equilibrium solubility by forming complexes with drugs so the system is not supersaturated, and thus, crystal growth and drug precipitation are inhibited. Considering all these hypotheses, the effect of PPIs on 
the equilibrium solubility of drugs should be investigated to better understand the role of PPIs in maintaining supersaturation.

Furosemide is practically insoluble in water, and its aqueous solubility at room temperature is 0.01825 $\mathrm{mg} / \mathrm{mL}[18,19]$. Furosemide is a weak acid and its solubility increases as the $\mathrm{pH}$ of the solution increases $[20,21]$. The solubility of furosemide in buffers and PPI containing buffers are given in Figures 2 and 3 . The $24 \mathrm{~h}$ equilibrium solubility of raw furosemide was $0.017 \pm 0.004$ and $3.62 \pm 0.201 \mathrm{mg} / \mathrm{mL}$ at $\mathrm{pH} 1.2 \mathrm{and} \mathrm{pH}$ 6.8 buffer solutions, respectively. As expected, furosemide solubility was higher in the alkaline $\mathrm{pH} 6.8 \mathrm{buffer}$ solution. In the literature, $48 \mathrm{~h}$ equilibrium solubility of furosemide was reported as 0.024 and $3.94 \mathrm{mg} / \mathrm{mL}$ at $\mathrm{pH} 1.2$ and $\mathrm{pH} 6.5$ buffer solutions, respectively, using shake-flask method [20]. Although our experimental conditions (room temperature, $24 \mathrm{~h}$ ) are different from the literature $\left(37^{\circ} \mathrm{C}, 48 \mathrm{~h}\right.$ ), our solubility results agree well with the reported values [20], indicating that $\mathrm{pH}$ is the determining factor for furosemide solubility. Furosemide equilibrium solubility increased in the presence of PPIs at $\mathrm{pH} 6.8$ buffer at least 2 -fold but at $\mathrm{pH}$ 1.2 buffer there was not such an increase. At pH 1.2 neither PPI type nor PPI concentration caused a significant increase in furosemide solubility, furosemide solubility increased from $0.017 \pm 0.004 \mathrm{mg} / \mathrm{mL}$ to $0.025 \pm 0.003 \mathrm{mg} / \mathrm{mL}, 0.024 \pm 0.002 \mathrm{mg} / \mathrm{mL}, 0.020 \pm 0.004 \mathrm{mg} / \mathrm{mL}$ and $0.022 \pm 0.002 \mathrm{mg} / \mathrm{mL}$ in $0.25 \%$ PVPK17, $0.05 \%$ PVPK17, 0.25\% HPMC, $0.05 \%$ HPMC ( $\mathrm{pH} 1.2$ buffer) solution, respectively ( $\mathrm{p}>0.05$ for all comparison). Effect PPI on the solubility was more pronounced for $\mathrm{pH} 6.8$ solutions. However, at $\mathrm{pH} 6.8$, both HPMC and PVPK17 increased furosemide solubility from $3.624 \pm 0.201 \mathrm{mg} / \mathrm{mL}$ to $10.164 \pm 0.218$ and $7.658 \pm 0.105 \mathrm{mg} / \mathrm{mL}$ for HPMC $(0.05 \%, \mathrm{w} / \mathrm{v})$ and PVPK17 $(0.25 \%, \mathrm{w} / \mathrm{v})$ solutions, respectively $(\mathrm{p}<0.0 .5)$. Nevertheless, different PPI concentrations did not alter the solubility of furosemide significantly ( $>>0.05)$. As shown in Figure 3, in both concentrations $(0.05 \%$ and $0.25 \%)$ at $\mathrm{pH} 6.8$ for HPMC and PVPK17 did not affect the solubility of furosemide. However, HPMC increased the solubility of furosemide more in both concentrations when compared to PVPK17.

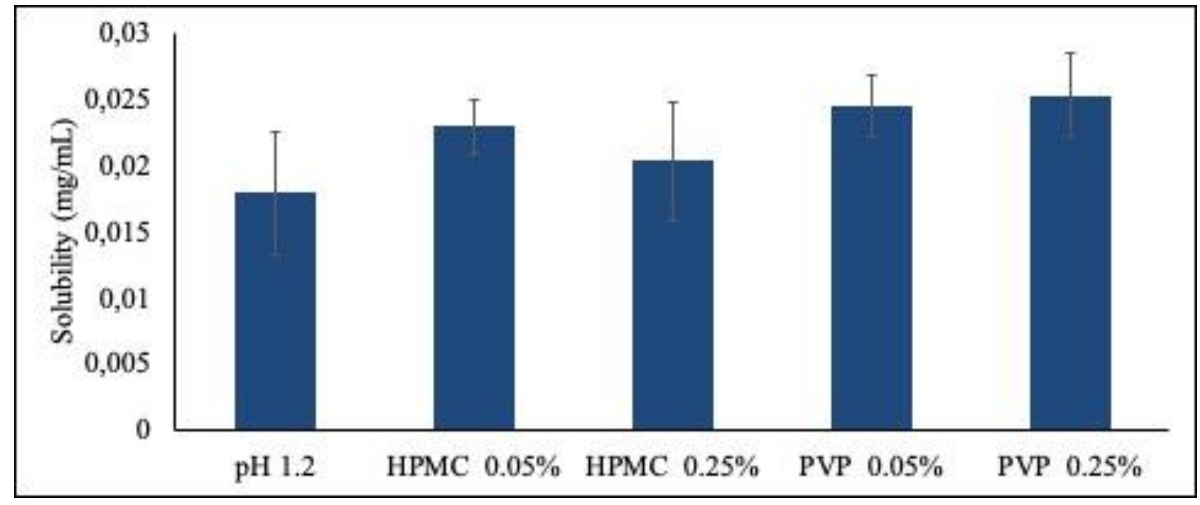

Figure 2. Solubility of furosemide in the absence and presence of PPIs at $\mathrm{pH} 1.2$ (mean \pm standard deviation (SD), $\mathrm{n}=3$ ).

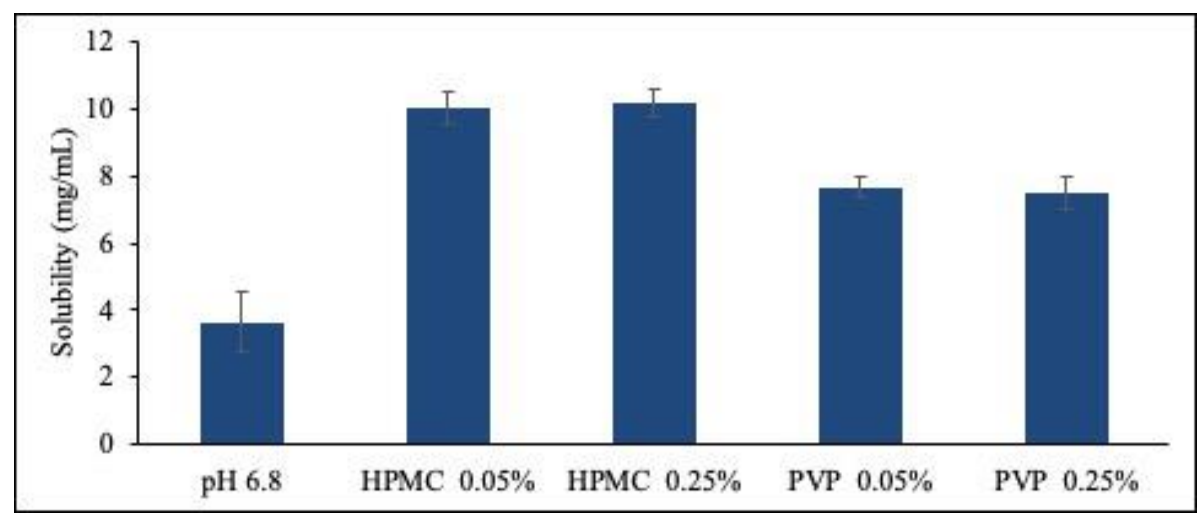

Figure 3. Solubility of furosemide in the absence and presence of PPIs at $\mathrm{pH} 6.8$ (mean \pm standard deviation (SD), $\mathrm{n}=3$ ). 
Scham et. al investigated crystal growth rate of felodipine in the presence of hydroxypropyl methylcellulose acetate succinate (HPMCAS) at $\mathrm{pH} 3.0$ and $\mathrm{pH} 6.8$ [22]. HPMCAS was reported to be more effective at $\mathrm{pH} 6.8$ due to its conformational state at this $\mathrm{pH}$. Based on the results it was concluded that due to ionization of HPMCAS at $\mathrm{pH} 6.8$, polymer chains were relaxed and crystal surface of drug was covered extensively by HPMCAS. However, due to globule formation by polymer chains at $\mathrm{pH} 3.0$, surface of drug crystal was accessible to other solutes in the solution. Thus, polymer chains could not prevent crystal nucleation and growth at $\mathrm{pH} 3.0$ as effectively as at $\mathrm{pH} 6.8$ [18]. Due to ionization and relaxation of PVPK17 and HPMC, polymer chains at $\mathrm{pH} 6.8$ cause a better crystal surface coverage, and as a result, solubility of furosemide increases.

\subsection{Effects of PPIs on furosemide supersaturation}

Furosemide is generally used as a model drug to develop novel formulation methods and for optimization studies due to its low and variable bioavailability [23]. Furosemide has a poor solubility which undergoes site-specific absorption in the stomach and the upper small intestine [24, 25]. Especially when the poor water-soluble drugs like furosemide contact with the gastrointestinal tract or dissolution media, they can trigger the drug to precipitate. To overcome these limitations and to enhance the bioavailability of these types of drugs, various polymeric precipitation inhibitors used to develop to protect the supersaturated state of the drug $[26,27]$.

In a previous study, it is indicated that the type and amount of PPIs effect the supersaturation state of drugs, and higher amounts of PPIs cause higher supersaturation degree [28]. Based on this observation, to improve the solubility of furosemide, in our study, we investigated the effect PVPK17 and HPMC at two different concentrations $(0.05$ and $0.25 \%)$ to maintain supersaturated state of furosemide. As shown in Figures 4 and 5, furosemide supersaturation was determined at $\mathrm{pH} 1.2$ and $\mathrm{pH} 6.8$ in the absence and presence of PPIs for $120 \mathrm{~min}$. For $\mathrm{pH} 1.2$, the supersaturation concentration of furosemide in all formulations was almost 6 times higher $(\sim 0.11 \mathrm{mg} / \mathrm{mL})$ than that of the equilibrium solubility $(0.017 \pm 0.0008 \mathrm{mg} / \mathrm{mL})$, indicating the importance of polymeric inhibitors to enhance the supersaturated drug concentration $(\mathrm{p}<0.05$ for all type and concentration of PPIs). In the presence of PPIs, the supersaturated concentration of furosemide increased significantly from $\mathrm{pH} 1.2$ to $\mathrm{pH} 6.8(\mathrm{p}<0.05)$. This result is expected because furosemide is a weak acid and its solubility is higher at basic pHs. However, as seen in Figure 5, the increase in the supersaturated furosemide concentration at $\mathrm{pH} 6.8$ was not pronounced when compared to equilibrium solubility. When HPMC concentration increased from $0.05 \%$ to $0.25 \%$, supersaturated furosemide concentration increased from $8.97 \mathrm{mg} / \mathrm{mL}$ to $10.50 \mathrm{mg} / \mathrm{mL}$, respectively. These results correlate well with the literature [29]. However, in the presence of PVPK17, furosemide concentration increased approximately 2.5 times when compared with equilibrium solubility, as shown in Figure 5. This result could be due to the higher affinity of the PVPK17 to hydrophilic compounds. As noted in a previous study, the dissolution rate of furosemide was lower in the presence of PVPK30 than other PPIs. Based on the results, the authors reported that only a 1.5-fold increase in dissolution rate may be due to the increased wettability and dispersibility of the hydrophobic drug by the more hydrophilic carrier [30].

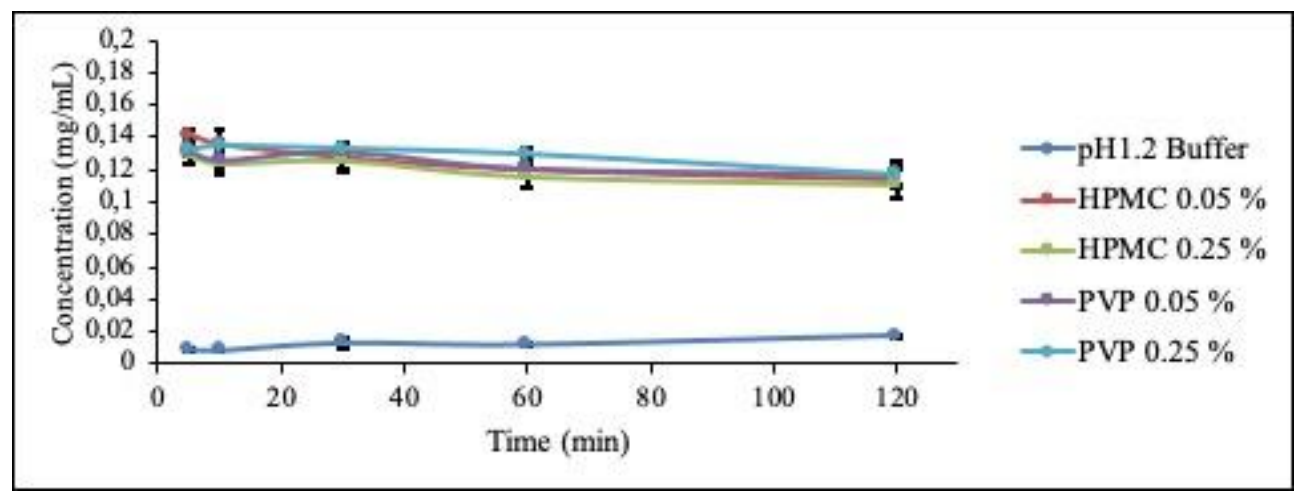

Figure 4. Furosemide concentration change as a function of time at $\mathrm{pH} 1.2$ buffer and PPI solutions prepared in the corresponding buffer (mean \pm standard deviation (SD), $n=3$ ). 


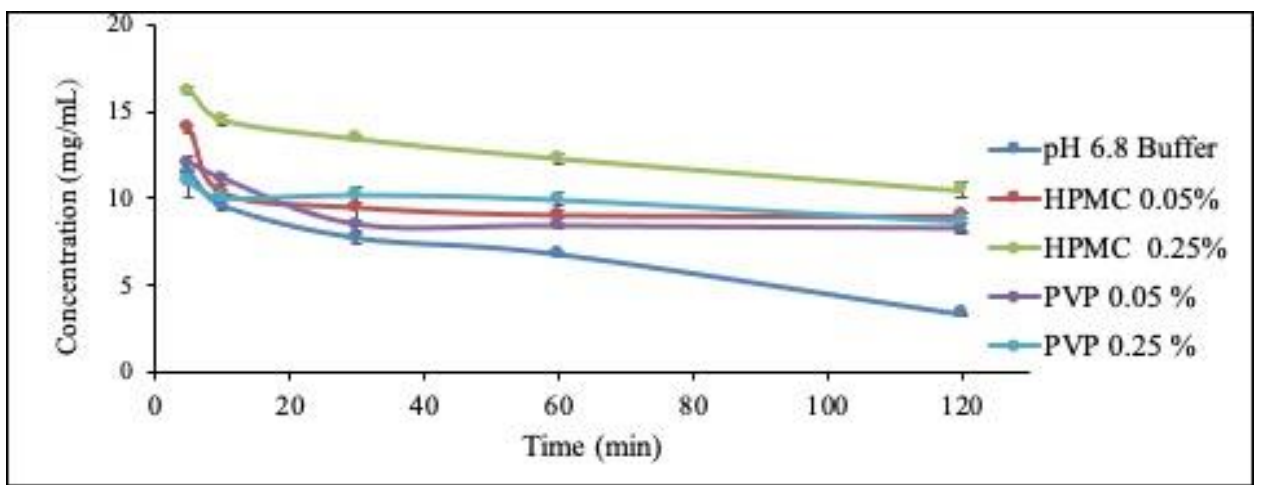

Figure 5. Furosemide concentration change as a function of time at $\mathrm{pH} 6.8$ buffer and PPI solutions prepared in the corresponding buffer (mean \pm standard deviation $(\mathrm{SD}), \mathrm{n}=3$ ).

\subsection{UV spectrophotometric method}

Validation parameters were summarized in Tables 1 and 2. A determination coefficient $\left(R^{2}\right)$ value of 0.998 was taken as an indication linearity of the analytical method (Table 1). Intra- and inter-day relative standard deviation (RSD) values were lower than $2 \%$ and also intra- and inter-day recovery data were satisfactory, demonstrating the precision and accuracy of the method.

Table 1. Linearity data of method $(n=6)$.

\begin{tabular}{ll}
\hline Regression equation & $\mathrm{y}=0.0533 \mathrm{x}-0.0005$ \\
Standard error of slope & 0.0002 \\
Standard error of intercept & 0.0003 \\
Determination coefficient $\left(\mathbf{R}^{2}\right)$ & 0.998 \\
Linearity range $(\boldsymbol{\mu g} / \mathrm{mL})$ & $0.5-10$ \\
Number of data $\mathbf{p o i n t s}$ & 6 \\
Limit of detection $(\boldsymbol{\mu g} / \mathrm{mL})$ & 0.04 \\
Limit of quantification $(\boldsymbol{\mu g} / \mathbf{m L})$ & 0.12 \\
\hline
\end{tabular}

Table 2. Accuracy and precision data $(n=3)$.

\begin{tabular}{|c|c|c|c|c|c|c|}
\hline Theoretical & Intra-day & & & Inter-day & & \\
\hline $\begin{array}{l}\text { drug amount } \\
(\mu \mathrm{g} / \mathrm{mL})\end{array}$ & $\begin{array}{l}\text { Founda } \\
(\mu \mathrm{g} / \mathrm{mL})\end{array}$ & $\begin{array}{l}\text { Accuracy }{ }^{a} \\
\text { Recovery } \\
(\%)\end{array}$ & $\begin{array}{l}\text { Precision }^{b} \\
\text { (RSD\%) }\end{array}$ & $\begin{array}{l}\text { Founda } \\
(\mu \mathrm{g} / \mathrm{mL})\end{array}$ & $\begin{array}{l}\text { Accuracya } \\
\text { Recovery } \\
(\%)\end{array}$ & $\begin{array}{l}\text { Precision }^{b} \\
\text { (RSD\%) }\end{array}$ \\
\hline 2 & $1.92 \pm 0.02$ & $96.15 \pm 0.94$ & 0.98 & $2.05 \pm 0.03$ & $102.41 \pm 1.43$ & 1.40 \\
\hline 4 & $3.97 \pm 0.06$ & $99.20 \pm 1.62$ & 1.64 & $3.97 \pm 0.03$ & $99.20 \pm 0.81$ & 0.82 \\
\hline 8 & $7.90 \pm 0.10$ & $98.77 \pm 1.29$ & 1.31 & $7.85 \pm 0.12$ & $98.07 \pm 1.51$ & 1.54 \\
\hline
\end{tabular}

\subsection{Effects of PPIs on viscosity}

PPIs can increase the viscosity of aqueous solutions and high viscosity lowers the diffusion of drug in the solution. Thus, viscosity increase can contribute to delaying of precipitation of supersaturated drug in solution. Viscosity values of PPI solutions at $\mathrm{pH} 6.8$ and 1.2 buffers were given in Figure 6. Viscosity of solutions was in the range of 2.2-3.7 centipoise, and was not influenced by the PPIs concentrations $(p>0.05)$. In supersaturation experiments (shown in Figure 4 and Figure 5), there was not a pronounced difference between PPI solutions regarding furosemide concentration at $\mathrm{pH} 1.2$ buffer. However, regardless of the concentration, HPMC was slightly superior to PVPK17 in terms of maintaining higher furosemide amount in the solution at $\mathrm{pH}$ 6.8. This could be attributed to the higher viscosity of HPMC than PVPK17 at pH 6.8, and therefore, retain slightly higher amounts of furosemide in HPMC solutions. 


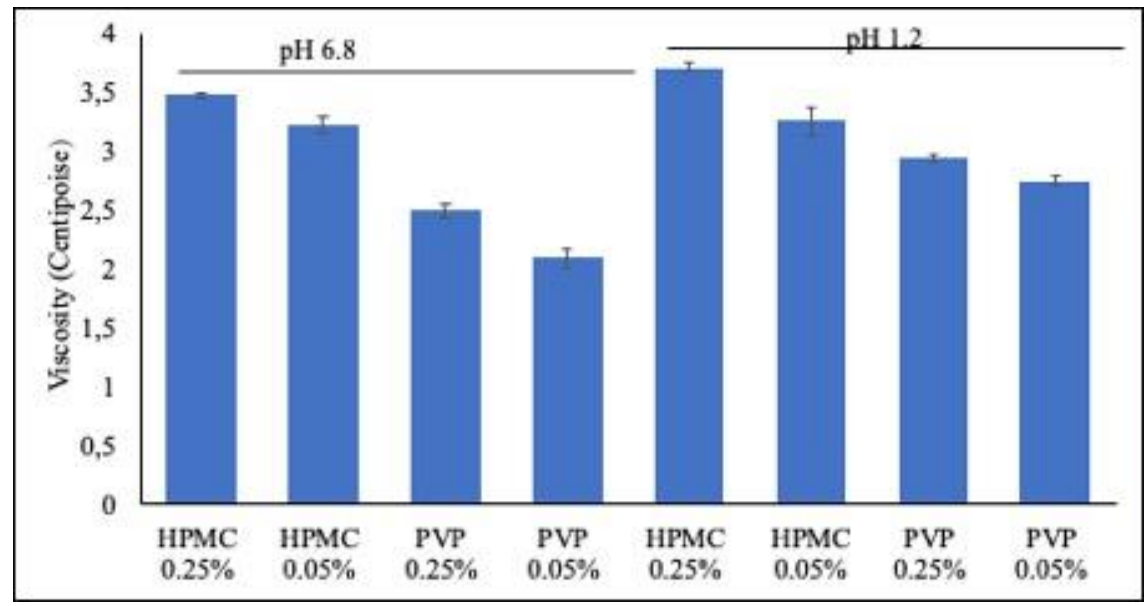

Figure 6. Viscosity of PPI solutions at $\mathrm{pH} 6.8$ buffer and $\mathrm{pH} 1.2$ buffer (mean $\pm S D, n=3$ ).

Ishikawa et al., evaluated the effect of HPMC on release profiles of a poorly water-soluble drug from tablets. The results showed that the increase in HPMC concentration in tablet increased the viscosity and delayed the dissolution of the drug with low water solubility from tablet [31], and supported our results with HPMC.

\section{CONCLUSION}

For development of a bioavailable product, solubility of furosemide (BCS Class IV drug) needs to be improved. This study was designed to solve solubility problem of furosemide using precipitation inhibitors such as PVPK17 and HPMC. Our results showed that furosemide PPIs can be used to enhance furosemide solubility and to maintain supersaturated state of furosemide. Based on these results, designing supersaturated formulations using PPIs which is a simple and effective method, can be useful and promising to enhance solubility of furosemide and other poorly water-soluble drugs.

\section{MATERIALS AND METHODS}

\subsection{Materials}

Furosemide was obtained as a gift sample from Deva Holding (Turkey). PVPK17 was purchased from by BASF (Germany). HPMC, dimethylsulfoxide (DMSO), sodium chloride, concentrated $\mathrm{HCl}$, disodium hydrogen phosphate, potassium dihydrogen phosphate and sodium hydroxide were obtained from Sigma Aldrich (Germany). All other chemicals were of analytical grade.

\subsection{Methods}

\subsubsection{Saturation solubility studies}

The shake flask method was used to determine the saturation solubility of furosemide in the absence and presence of PVPK17/HPMC at $\mathrm{pH} 1.2$ and 6.8. After preparation of $\mathrm{pH} 1.2$ and 6.8 buffer solutions according to United States Pharmacopeia (USP) [32], PVPK17 and HPMC were dissolved in pH 1.2 and pH 6.8 buffers to achieve concentrations of 0.05 and $0.25 \%$ for both. Subsequently, an excess amount of furosemide above its saturation solubility at $\mathrm{pH} 1.2$ and $6.8(100 \mathrm{mg})$ was added to the solutions of PPIs. The mixtures were agitated at a speed of $60 \mathrm{rpm}$ for $24 \mathrm{~h}$ at room temperature. At the end of $24 \mathrm{~h}$, sample was withdrawn and filtered using a $0.45 \mu \mathrm{m}$ PTFE syringe filter. Furosemide concentration was determined by UV spectrophotometry.

\subsubsection{Supersaturation studies}

Solvent-shift method was used to create the supersaturated state [33]. Furosemide solution (381.6 mg in $1.2 \mathrm{~mL}$ DMSO) was added dropwise to a glass vial containing the $20 \mathrm{~mL}$ of the medium of interest ( $\mathrm{pH} 1.2$ buffer, pH 6.8 buffer in the absence/presence of PVPK17/HPMC) and stirred continuously at room temperature at $600 \mathrm{rpm}$. Resulting drug amount in each vial was at least 5 times higher than the solubility of furosemide in both $\mathrm{pH} 1.2$ and $\mathrm{pH} 6.8$ buffer solutions. The concentrations of PPIs were used as $0.05,0.25 \%$ 
both for PVPK17 and HPMC. Samples $(1 \mathrm{~mL})$ were withdrawn at predetermined sampling intervals $(5,10$, 30, 60, $120 \mathrm{~min}$ ), and were filtered using a $0.45 \mu \mathrm{m}$ PTFE syringe filter. Furosemide concentration in samples was determined by UV spectrophotometry.

\subsubsection{UV spectrophotometric method}

The analysis was carried out using a Shimadzu UV-visible spectrophotometer system (Shimadzu 1800, Japan) with quartz cuvette. Samples were filtered through a $0.45 \mu \mathrm{m}$ PTFE syringe filter, and then furosemide concentrations in filtrates were determined at $274 \mathrm{~nm}$ [34]. Quantitative analysis of furosemide solubility results and furosemide concentration change as a function of time in different buffers were measured by this method. At concentrations of $0.5,1,2,4,8,10 \mu \mathrm{g} / \mathrm{mL}$ furosemide solutions were prepared in $0.1 \mathrm{M} \mathrm{NaOH}$ solution to obtain the calibration curve. The analytical method was validated as to linearity, precision, and accuracy parameters according to ICH guidelines [35].

\subsubsection{Determination of viscosity}

The viscosity measurements of PPI solutions (0.05 or $0.25 \%$ HPMC and PVPK17 solutions at $\mathrm{pH} 1.2$ and $\mathrm{pH} 6.8$ buffer solutions) were performed with an Ubbelohde viscometer using a capillary based method for measuring viscosity at room temperature. This viscometer is recommended for higher viscosity cellulosic polymer solutions. The flow times were determined from the average of three measurements and viscosities were calculated by Equation 1 .

$$
\text { ๆ }=\text { k.t.d } \quad \text { Eq.1 }
$$

Dynamic Viscosity: Poise (ๆ)

$\mathrm{k}$ : Viscometer constant

t: Flow time (sec)

d: Density $\left(\mathrm{g} / \mathrm{cm}^{3}\right)$

\subsubsection{Statistical analysis}

All tabulated results were given as mean \pm standard deviation. GraphPad Prism 6 was used for comparing the solubility and viscosity results by Student's t-test, and a p value less than 0.05 was considered significant.

\section{Acknowledgements: None.}

Author contributions: Concept - S.S., I.V.; Design - T.G., N.O., A.K., S.S., I.V.; Supervision - S.S., I.V.; Materials T.G., N.O., A.K., S.S., I.V.; Data Collection and/or Processing - T.G., N.O., A.K., S.S., I.V.; Analysis and/or Interpretation - T.G., N.O., A.K.; Literature Search - T.G., N.O., A.K., S.S., I.V.; Writing - T.G., N.O., A.K., S.S., I.V.; Critical Reviews - T.G., N.O., A.K., S.S., I.V.

Conflict of interest statement: The authors declared no conflict of interest.

\section{REFERENCES}

[1] Khadka P, Ro J, Kim H, Kim I, Kim JT, Kim H, Cho JM, Yun G, Lee J. Pharmaceutical particle technologies: an approach to improve drug solubility, dissolution and bioavailability. Asian J Pharm Sci. 2014; 9(6): $304-316$. [CrossRef]

[2] Prajapati BG, Patel MM. Conventional and alternative pharmaceutical methods to improve oral bioavailability of lipophilic drugs. Asian J Pharm. 2007; 1(1): 1-8.

[3] Miller JM, Beig A, Carr RA, Spence JK, Dahan A. A win-win solution in oral delivery of lipophilic drugs: supersaturation via amorphous solid dispersions increases apparent solubility without sacrifice of intestinal membrane permeability. Mol Pharm. 2012; 9(7): 2009-2016. [CrossRef]

[4] Warren DB, Benameur H, Porter CJH, Pouton CW. Using polymeric precipitation inhibitors to improve the absorption of poorly water-soluble drugs: a mechanistic basis for utility. J Drug Target. 2010; 18(10): 704-731. [CrossRef] 
[5] Price DJ, Ditzinger F, Koehl NJ, Jankovic S, Tsakiridou G, Nair A, Holm R, Kuentz M, Dressman JB, Saal C. Approaches to increase mechanistic understanding and aid in the selection of precipitation inhibitors for supersaturating formulations - a pearrl review. J Pharm Pharmacol. 2019; 71(4): 483-509. [CrossRef]

[6] Xu S, Dai WG. Drug precipitation inhibitors in supersaturable formulations. Int J Pharm. 2013; 453(1): 36-43. [CrossRef]

[7] Amidon GL, Lennernäs H, Shah VP, Crison JR. A theoretical basis for a biopharmaceutic drug classification: the correlation of in vitro drug product dissolution and in vivo bioavailability. Pharm Res. 1995; 12(3): 413-420. [CrossRef]

[8] Wu CY, Benet LZ. Predicting drug disposition via application of bcs: transport/absorption/elimination interplay and development of a biopharmaceutics drug disposition classification system. Pharm Res. 2005; 22(1): 11-23. [CrossRef]

[9] Kashyap S, Singh A, Mishra A, Singh V. Enhanced sustained release of furosemide in long circulating chitosanconjugated plga nanoparticles. Res Pharm Sci. 2019; 14(2): 93-106. [CrossRef]

[10] Boles Ponto LL, Schoenwald RD. Furosemide (Frusemide) a pharmacokinetic/pharmacodynamic review (part I). Clin Pharmacokinet. 1990; 18(5): 381-408. [CrossRef]

[11] Klausner EA, Lavy E, Stepensky D, Cserepes E, Barta M, Friedman M, Hoffman A. Furosemide pharmacokinetics and pharmacodynamics following gastroretentive dosage form administration to healthy volunteers. J Clin Pharmacol. 2003; 43(7): 711-720. [CrossRef]

[12] Nielsen LH, Rades T, Müllertz A. Stabilisation of amorphous furosemide increases the oral drug bioavailability in rats. Int J Pharm. 2015; 490(1-2): 334-340. [CrossRef]

[13] Patel DD, Anderson BD. Effect of precipitation inhibitors on indomethacin supersaturation maintenance: mechanisms and modeling. Mol Pharm. 2014; 11(5): 1489-1499. [CrossRef]

[14] Tran P, Pyo YC, Kim DH, Lee SE, Kim JK, Park JS. Overview of the manufacturing methods of solid dispersion technology for improving the solubility of poorly water-soluble drugs and application to anticancer drugs. Pharmaceutics. 2019; 11(3): 1-26. [CrossRef]

[15] Kanikkannan N. Technologies to improve the solubility, dissolution and bioavailability of poorly soluble drugs. J Anal Pharm Res. 2018; 7(1): 44-50. [CrossRef]

[16] Brouwers J, Brewster ME, Augustijns P. Supersaturating drug delivery systems: the answer to solubility-limited oral bioavailability? J Pharm Sci. 2009; 98(8): 2549-2572. [CrossRef]

[17] Fong SY, Bauer-Brandl A, Brandl M. Oral bioavailability enhancement through supersaturation: an update and meta-analysis. Expert Opin Drug Deliv. 2017; 14(3): 403-426. [CrossRef]

[18] Shin SC, Kim J. Physicochemical characterization of solid dispersion of furosemide with tpgs. Int J Pharm. 2003; 251(1-2): 79-84. [CrossRef]

[19] Dalal L, Allaf AW, El-Zein H. Formulation and in vitro evaluation of self-nanoemulsifying liquisolid tablets of furosemide. Sci Rep. 2021; 11: 1315. [CrossRef]

[20] Granero G, Longhi MR, Mora MJ, Junginger HE, Midha KK, Shah VP, Stavchansky S, Dressman JB, Barends DM. Biowaiver monographs for immediate release solid oral dosage forms: furosemide. J Pharm Sci. 2010; 99(6): 25442556. [CrossRef]

[21] Kaynak MS, Sahin S. Development and validation of a rp-hplc method for determination of solubility of furosemide. Turk J Pharm Sci. 2013; 10(1): 25-34.

[22] Schram CJ, Beaudoin SP, Taylor LS. Impact of polymer conformation on the crystal growth inhibition of a poorly water-soluble drug in aqueous solution. Langmuir. 2015; 31(1): 171-179. [CrossRef]

[23] Grahnén A, Hammarlund M, Lundqvist T. Implications of intraindividual variability in bioavailability studies of furosemide. Eur J Clin Pharmacol. 1984; 27(5): 595-602. [CrossRef]

[24] Iannuccelli V, Coppi G, Leo E, Fontana F, Bernabei MT. Pvp solid dispersions for the controlled release of furosemide from a floating multiple-unit system. Drug Dev Ind Pharm. 2000; 26(6): 595-603. [CrossRef]

[25] Markovic M, Zur M, Ragatsky I, Cvijić S, Dahan A. BCS Class IV Oral drugs and absorption windows: Regionaldependent intestinal permeability of furosemide. Pharmaceutics. 2020; 12(12): 1-16. [CrossRef]

[26] Zhu R. PhD Thesis. Investigation of enhancement of furosemide solubilization with cyclodextrins and a novel 
octenyl succinate anhydride starch. Pharmaceutical Sciences, College of Graduate Health Sciences, University of Tennessee, Memphis, TN, USA, 2012. [CrossRef]

[27] Bannow J, Yorulmaz Y, Löbmann K, Müllertz A, Rades T. Improving the drug load and in vitro performance of supersaturated self-nanoemulsifying drug delivery systems (super-SNEDDS) using polymeric precipitation inhibitors. Int J Pharm. 2020; 575: 118960. [CrossRef]

[28] Abu-Diak OA, Jones DS, Andrews GP. An investigation into the dissolution properties of celecoxib melt extrudates: understanding the role of polymer type and concentration in stabilizing supersaturated drug concentrations. Mol Pharm. 2011; 8(4): 1362-1371. [CrossRef]

[29] Takács-Novák K, Szőke V, Völgyi G, Horváth P, Ambrus R, Szabó-Révész P. Biorelevant solubility of poorly soluble drugs: rivaroxaban, furosemide, papaverine and niflumic acid. J Pharm Biomed Anal. 2013; 83: 279-285. [CrossRef]

[30] Gahandule M, Gadhave MV. Enhancement of solubility and dissolution rate of furosemide by ternary solid dispersion technique. Int J Adv Pharm. 2016; 5(6): 140-150.

[31] Ishikawa T, Watanabe Y, Takayama K, Endo H, Matsumoto M. Effect of hydroxypropylmethylcellulose (hpmc) on the release profiles and bioavailability of a poorly water-soluble drug from tablets prepared using macrogol and hpmc. Int J Pharm. 2000; 202(1-2): 173-178. [CrossRef]

[32] United States Pharmacopeia and National Formulary (USP 30-NF 25). United States Pharmacopeial Convention; 2007.

[33] Bevernage J, Brouwers J, Brewster ME, Augustijns P. Evaluation of gastrointestinal drug supersaturation and precipitation: strategies and issues. Int J Pharm. 2013; 453(1): 25-35. [CrossRef]

[34] Ai H, Jones SA, de Villiers MM, Lvov YM. Nano-encapsulation of furosemide microcrystals for controlled drug release. J Control Release. 2003; 86(1): 59-68. [CrossRef]

[35] International conference on harmonisation of technical requirements for registration of pharmaceuticals for human use. Validation of analytical procedures: text and methodology, Q2(R1); ICH harmonised tripartite guideline 2005. https://database.ich.org/sites/default/files/Q2\%28R1\%29\%20Guideline.pdf, (accessed on 04 March 2021).

This is an open access article which is publicly available on our journal's website under Institutional Repository at http://dspace.marmara.edu.tr. 